\title{
Sailing and sports medicine: a literature review
}

J B Allen, M R De Jong

Br J Sports Med 2006;40:587-593. doi: 10.1136/bjsm.2002.001669

Sailing medicine has been mainly addressed by healthcare professionals who happen to sail. Although there has been an increase in the number of studies of various aspects of sailing over the last 15 years, efforts to advance evidence based knowledge of sailing and sports medicine face unique obstacles. Recent interest in research by groups such as Olympic and America's Cup teams has produced beneficial changes.

See end of article for authors' affiliations .....................

Correspondence to: Dr Allen, SailSportMed Inc, Wilmington, NC 28403, USA; aasail@aol. com

Accepted 9 February 2006 Published Online First 17 March 2006 significance, current studies, and opinion pieces addressing topics of interest, as they were relevant to the scope of this article.

\section{INJURIES}

Injuries and illness related to sailing are not unusual. Physical demands of sailing vary with boat class (table 1) and crew position and thus injuries may differ on the basis of the specific job stressors. $^{2}{ }^{3}$

Injuries may result from a lack of general fitness, overuse, overtraining, or macrotraumatic accidents. ${ }^{2-6}$ Many actions in sailing are sudden and sporadic, placing muscles at high risk by performing explosive, powerful moves, often when they are not warmed up. ${ }^{24}$ Sudden, strong movements in hiking (fig 1) may lead to back and knee problems, and constant mainsheet handling can result in shoulder and arm injuries. ${ }^{8}$ Physical actions around a sailboat are often awkward, resulting in rotating, hyperextending, locking, or twisting of joints. ${ }^{6}$ Lifting poses a particular risk, with difficulty maintaining proper form on a moving vessel. ${ }^{4}{ }^{9}$ Inherent postural problems in many crew positions play a role in musculoskeletal issues. ${ }^{249}{ }^{10}$ Inadequate fitness training may exacerbate common muscular imbalances associated with changing forces on opposing muscle groups while sailing. ${ }^{49}$ Lack of warming up, stretching, and cooling down surrounding a race may also increase the risk of injury. ${ }^{4}{ }^{911}$

\section{Small boats}

Several studies have sought to quantify the incidence of sailing injuries in various populations. A 2002 review of the Brazilian Olympic team by Moraes et al ${ }^{12}$ revealed that the most common painful areas were lower back $(52.9 \%)$, other back areas (41.2\%), knees (25-32\%), right thigh $(26.5 \%)$, neck (23.5\%), right shoulder $(23.5 \%)$, and forearm or elbow (20.6\%). According to Legg et $\mathrm{al}^{13}, 57 \%$ of New Zealand Olympic sailors in 1997 reported injury in the preceding three years, including lower back $(45 \%)$, knee $(22 \%)$, shoulder $(18 \%)$, and arm $(15 \%)$. The most common injuries in Kiel week regatta sailors were back pain $(44 \%)$ and knee pain $(30 \%) .{ }^{8}$ A retrospective review of hospital records during Kiel week from 1984-87 showed that sailing injuries requiring hospital care are three times more common in male competitors and twice as likely from sailing dinghies than keelboats, involving injuries such as open wounds (31.3\%), hand injuries $(31.3 \%)$, head

Abbreviations: $H R$, heart rate; $M V C$, maximum voluntary contraction; $\mathrm{VO}_{2} \mathrm{MAX}$, maximal oxygen uptake 
Table 1 Brief description of selected boats mentioned in the review

\begin{tabular}{llllll}
\hline Boat & $\begin{array}{l}\text { Length } \\
(\mathbf{m})\end{array}$ & $\begin{array}{l}\text { Weight } \\
(\mathbf{k g})\end{array}$ & $\begin{array}{l}\text { No of } \\
\text { sailors }\end{array}$ & $\begin{array}{l}\text { Upwind sail area } \\
\left(\mathbf{m}^{2}\right)\end{array}$ & $\begin{array}{l}\text { Downwind sail } \\
\text { area }\left(\mathbf{m}^{2}\right)\end{array}$ \\
\hline AC Class & 24.0 & 25000 & $16-17$ & 220 (main only) & 720 \\
Volvo 60 & 19.5 & 14000 & 12 & 200 & 417 \\
Laser & 4.23 & 59.0 & 1 & 7.06 & 7.06 \\
Finn & 4.54 & 144.7 & 1 & 10.0 & 10.0 \\
Star & 6.92 & 671.3 & 2 & 26.7 & 7.7 \\
Europe & 3.35 & 45.0 & 1 & 7.2 & 12.7 \\
470 & 4.70 & 120.0 & 2 & 4.7 & 2 \\
\hline
\end{tabular}

injuries $(22.1 \%)$, contusions $(19.7 \%)$, and various fractures $(15.1 \%) .{ }^{11}$

\section{Boardsailing}

Studies specific to boardsailing have suggested an injury rate of 0.22 per 1000 hours of participation ${ }^{8}$ and an incidence of 1 per 1000 sailing days. ${ }^{14}$ Retrospective surveys of elite boardsailors in 1984 and 1989 showed similar injury rates. ${ }^{15} 16$ The most commonly affected areas were skin, shins, feet, back, and forearms, with injuries such as abrasions, lacerations, and sprains/strains. According to a 2002 review, the most commonly injured or painful areas are the lower extremities (44.6\%), upper extremity (18.5\%), head and neck $(17.8 \%)$, and trunk $(16.0 \%) .{ }^{14}$ The most common types of injury are sprains $(26.3 \%)$, lacerations $(21.2 \%)$, contusions (16.2\%), and fractures (14.2\%).

\section{Big boats}

Sailors participating in America's Cup match racing events or offshore endurance races such as the Volvo Ocean Race and the BT Global Challenge often have to deal with injuries. ${ }^{3}{ }^{17-19}$ Epidemiological studies of injuries in America's Cup sailing have increased recently, with the growing recognition and value placed on the human performance factor. Allen and coworkers $^{2}{ }^{19}$ suggested in a pilot study during the 1995 America's Cup that the most common injuries on the female team of America $^{3}$ were lower back and shoulder injuries, most of which were microtraumatic and related to overuse. Injury patterns were specific to crew position; proper fitness training and ergonomics for injury prevention were deemed essential. A comprehensive follow up study in 2000 by Allen et $a l^{319}$ with contributions from all 12 America's Cup teams determined that bowmen and jib winch grinders (fig 2) were injured most often, that $76 \%$ were soft tissue injuries, and that the most common injury locations were the lumbar spine $(16 \%)$, shoulder $(16 \%)$, knee $(10 \%)$, cervical spine $(8 \%)$, and hand $(7 \%)$. Injury mechanisms on the boat included grinding $(30 \%)$, lifting $(24 \%)$, and impact from objects (16\%); however, $18 \%$ of injuries occurred off the boat

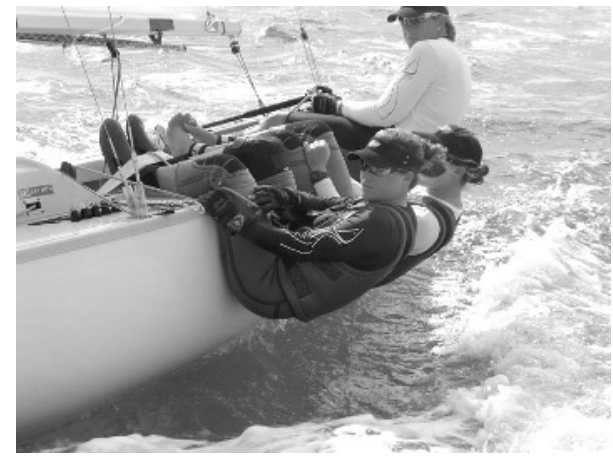

Figure 1 Demonstration of hiking. The subjects have given permission for the photograph to be published. during fitness training. Neville $e t \mathrm{al}^{20}$ also reported entrapment of the posterior interosseous nerve during America's Cup training, caused by overload of the upper extremity, particularly the supinator muscle, while pulling sails, grinding, and arm ergometer training.

A study involving one team of 36 men during the 2003 America's Cup documented 220 injuries and 119 illnesses over 74 weeks of sailing and training, with an incidence of 5.7 injuries/1000 sailing hours. ${ }^{21}$ The upper limb was most commonly injured (40\%), followed by spine and neck (30\%); most injuries were sprains/strains/tendinopathies (47\%), with overuse as the most common mechanism of injury, similar to the 2000 study. Grinders and bowman had the highest incidence of overall injury and sailing injury respectively.

Offshore endurance races pose unique challenges for injury prevention, mechanisms, and treatment. ${ }^{17}{ }^{18} 22$ Spalding et al ${ }^{18}$ conducted a prospective investigation of injuries during the 2001-2002 Volvo Ocean Race. Lower back pain, shoulder pain, neck pain, and skin lesions were most problematic. Bowmen (2.9 injuries/leg) and helmsmen (2.6 injuries/leg) were most subject to injury. Helmsmen were prone to develop upper extremity overuse problems, such as carpal tunnel syndrome, due to demands of heavy weather steering. Similar patterns of injury were recorded by Price et $a l^{17}$ during the BT Global Challenge Round the World Yacht Race in 1996-1997.

\section{Sailors with disabilities}

Limited studies have been performed on injuries to disabled sailors, but preliminary studies suggest that they are similar to those in able bodied sailing. A 1999 survey of sailors in the International Foundation for Disabled Sailing World Championship, with 24 teams and multiple disability types, showed an injury incidence of $6.34 \%$; the most common injuries were sprains/strains/overuse $(68 \%){ }^{23}$ Although the spine was commonly injured $(20 \%)$, the upper extremity sustained more injuries than in able bodied sailing $(60 \%)$ because of the increased weight bearing on the upper

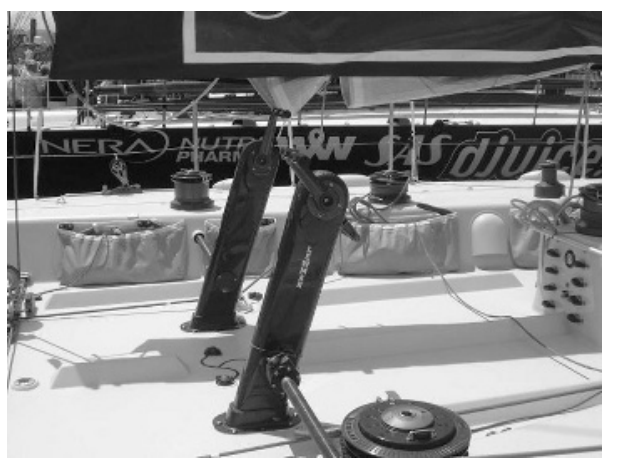

Figure 2 Pedestal winches for grinding. 
extremities in disabled athletes, especially in spinal cord injuries. Unique injuries include autonomic dysreflexia in spinal cord injuries and skin/pressure sore problems. The safety in sailing study performed at the 2004 Athens Paralympic Games for the International Paralympic Committee suggests that specific education about injury prevention and safety measures is essential before hosting regattas involving disabled sailors. ${ }^{24}$

\section{Back pain}

Back pain is common in sailing, from dinghy sailors to America's Cup and Volvo Ocean Race teams. ${ }^{25} 818$ 25-27 In dinghy hiking, problems may result from overarching the lower back because of weak abdominal muscles, or simply from overuse and abnormal spinal stresses during sailing. ${ }^{25}$ When hiking or using a harness to counterbalance the boat, it may be safest to keep the back straight, depending on the hiking style being performed. ${ }^{5}$ Using electromyographic analysis to evaluate static hiking, Hall et al ${ }^{26}$ have suggested that the best harnesses include rigid padding, shoulder through buttock support, and leg strap supports, although individual body variations are key in finding the best fit.

Locke and Allen ${ }^{28}$ examined seven elite boardsailors with chronic lower back pain which occurred only while participating in the sport. After normal examinations and radiographs, computed tomography scans revealed two pars defects, two disc protrusions, and two disc bulges at L5-S1, representing a high occurrence rate for their age group. Back pain in big boat sailing is associated with crew positions, such as the winch man undergoing repetitive motion and positional strain of grinding or the bowman and sewerman lifting spinnaker poles and heavy sails. ${ }^{3} 19$

\section{INJURY PREVENTION AND RETURN TO PLAY}

Injury prevention is best addressed through appropriate fitness training and properly caring for previous injuries. There is limited research to support injury prevention programmes in sailing, but it may be effective to include flexibility, hip flexor mobility, and core stability programmes to reduce injury risk. ${ }^{25}$ Addressing ergonomic developments, particularly in big boat design, also holds potential for injury prevention. ${ }^{3}$

Returning to play depends on the nature of injury and the physical demands for which the athlete is returning to sail. ${ }^{2} \mathrm{~A}$ survey of Mayo Clinic orthopaedic surgeons found that most would allow sailing after hip or knee arthroplasty, although many said that it would depend on the circumstances. ${ }^{29} \mathrm{~A}$ recommended contraindication is a history of repeated loss of consciousness, such as due to epilepsy or cerebrovascular disease. ${ }^{30}$ Within the Paralympic Games and disabled sailing, there are many people racing competitively with little difficulty. In all sailing situations, safety is essential, and it is important that adequate knowledge and education is available to all who participate in or organise the sport. ${ }^{24}$

\section{ILLNESS}

Various illnesses have been documented during ocean endurance races and day sailed regattas, including the America's Cup. ${ }^{18} 2122$ Most common are viral illnesses, which are difficult to contain as they spread through the teams.

Environmental issues such as hyperthermia, heat illness, dehydration, sea sickness, and sun related problems are familiar in sailing. ${ }^{522}$ 30-34 Hypothermia, water immersion, near drowning, and other marine emergencies are also obvious risks at sea. ${ }^{33}{ }^{35-38}$ Although these topics are beyond the scope of this article, illness and environmental influences may affect injuries in sailing, and appropriate prevention, including proper clothing, adequate nutrition, and safety measures, are recommended..$^{245-40}$

\section{PERFORMANCE ENHANCEMENT}

Human performance and sport science affect all athletes and their sports, including the sailing athlete. Performance enhancement teams are often formed in order to bring together expertise in all components-fitness training, physiology and biomechanics, nutrition, and sports psychology - to assist the sailors and teams in achieving their goals. As each of these components has a direct effect on injury prevention and treatment, rehabilitation, and return to play, articles were reviewed in each area and are briefly commented on below.

\section{Fitness training}

Overview

With physical fitness joining boat speed and tactical intelligence as the main determinants of sailing performance, $^{7142}$ the issue of fitness training for sailors is accompanied by many opinion articles. Yet only a 1997 study by Legg et al $^{13}$ has published training practices of sailors. They surveyed 28 New Zealand Olympic sailors, 61\% of whom underwent strength/circuit training, 36\% addressed flexibility, $75 \%$ trained aerobically on land, and $86 \%$ performed onwater aerobic training while sailing. Studying 25 Olympic sailors with self prescribed strength, endurance, and flexibility programmes, Legg et $a l^{43}$ found that some groups exhibited significant changes in body weight, skinfolds, flexibility, aerobic endurance, and strength, although the results were inconsistent.

Strength, power, muscle endurance, cardiovascular fitness, weight management, flexibility, and agility all play roles in sailors' training regimens. ${ }^{71}{ }^{43-47}$ Proper warm up and cool down is essential, and appropriate stretching and flexibility can optimise balance and mobility while decreasing muscle tension and unloading repetitively stressed muscles. ${ }^{10}{ }^{48-51}$ Agility exercises may improve hand-eye coordination and the efficiency of movement about a sailboat. ${ }^{41}$ Weightlifting routines should involve commonly used muscle groups plus their antagonists to maintain proper balance of strength; this should include a core workout. ${ }^{10}{ }^{48} 50$ Literature from medical journals and sailing periodicals have offered extensive routines, with recommendations to rotate targeted muscle groups on different days. ${ }^{44} 45480$

Aerobic training and fitness has been shown to be directly related to sailors' reaction speed to wind shifts, ${ }^{8}$ as well as enhanced endurance, decision making, and concentration, particularly in the later stages of races. ${ }^{71}{ }^{50}$ Physical and mental recovery between races and regattas may also improve with cardiovascular fitness. ${ }^{7}$ Whereas some authors feel that rowing is the most applicable aerobic activity for sailors, others allow for cycling, swimming, or running. ${ }^{41} 43454752$

\section{Fitness specifics}

Various boat classes, crew positions, racing conditions, and baseline fitness levels make it unfeasible to provide a uniform recommendation for fitness requirements. ${ }^{7} 104144-46$ Sailing dinghies and small keelboats requires aerobic endurance and muscular strength and endurance. ${ }^{41}{ }^{45}$ Sailors who hike rely on muscle groups in the thighs, abdominals, hips, and arms, whereas sailors on a trapeze may focus more on upper body strength and endurance, aerobic endurance, and agility. ${ }^{74} 45$ For any boat size, crew members regularly involved with sail trimming require highly trained arms, shoulders, and upper back. ${ }^{7}$ Grinders and many other big boat sailors should address aerobic endurance as well as muscular strength, power, and endurance, particularly in the upper body. ${ }^{744653}$

The timing of fitness training is important, whether that entails maintaining fitness in the off-season or reducing heavy training loads before regattas. ${ }^{6} 73044454$ The training concept of periodisation allows peak fitness when it is most 
needed, with background training starting six months before the target date. ${ }^{54}$ Cunningham $^{41}{ }^{45}$ and Blackburn $^{54}$ have detailed the progression of training programmes used by the Olympic sailors in their respective countries, and may provide further opinion based insight for the reader.

Articles specific to training for boardsailors have also advocated use of periodisation..$^{55}$ Training should involve the shoulder girdle, as boardsailing requires sustained isometric action of the pectoralis major, deltoid, and scapular stabilisers. ${ }^{8}$ Although studies correlating training or physiological variables with performance results are lacking, some authors contend that performance capacity is directly related to appropriate training. ${ }^{16}$

\section{Weight management}

Weight management issues for sailors usually involve reaching a perceived ideal mass for racing a small boat or meeting weight limits of a one design class. ${ }^{40}$ Weight loss should be gradual, focusing on reduced energy intake while increasing aerobic exercise. ${ }^{41}{ }^{44}$ Awareness of problems associated with the female athlete triad in women sailors is also critical. ${ }^{40}$ Increasing strength while decreasing body weight may be accomplished by adding muscle mass by performing higher reps of moderate weight loads. ${ }^{44}$ Healthy weight gain can be difficult, as increasing body fat is not ideal for an athlete; it is preferable to add muscle mass by increasing energy intake and weightlifting. ${ }^{41}$ Increasing body weight and endurance can also be challenging; the key may be holding separate strength and endurance sessions. ${ }^{44}$

Although lightweight sailors tend to sail lighter displacement boats whereas heavier sailors predominate in the heavier classes, there is much speculation about ideal sizes. ${ }^{41} 52$ Profiling Danish Olympic class sailors, BojsenMoller et $a l^{56}$ reported that the mean (SD) weight of Laser sailors was $80.3(2.7) \mathrm{kg}$ and that of Finn and Star sailors was 93.5 (10.8) kg. Shephard ${ }^{51}$ has referenced a review of the Ontario sailing team in which the best sailors possessed a lower body fat percentage than the average team member, but no other differences prevailed. Gold medal winners in the Montreal Olympics were taller, but not heavier, than other participants. Shephard concludes that "it is wrong to look for a single optimal profile."

\section{Physiology}

Opinions on training regimens for sailors have traditionally lacked valid scientific basis because of a paucity of studies on the physiology of sailors and of the sailing activity. The knowledge base is gradually improving with an increase in studies, although this is predominantly in dinghy sailing. Here we will review available studies and additional opinions, analysing the physiological profiles of sailors, the effects of physiological variables on sailing performance, and the physiology of various aspects of racing sailboats.

\section{Physiological profiles of elite sailors Body fat}

In 2003, Vangelakoudi and Vogiatzis ${ }^{57}$ reported the measured body fat of eight elite male Laser sailors (fig 3), comparing them with eight club level controls. The elite sailors actually possessed a higher percentage of body fat ( $10.5(4.1) \% \vee 8.6$ $(4.3) \%)$. Bernardi et $a^{53}$ evaluated body fat of 18 America's Cup sailors; it ranged from $10.3 \%$ for bowmen and trimmers to $12.9 \%$ for grinders and $14.9 \%$ for other crew. A 2003 America's Cup study of 36 male sailors found a mean (SD) body fat of $12.5(5.4) \%$.

\section{Maximal oxygen uptake ( $\left.\mathrm{VO}_{2} \mathrm{MAX}\right)$}

Studying sailors from eight classes in the 1992 Olympics, Larsson et $a^{58}$ reported mean (SD) $\mathrm{VO}_{2} \mathrm{MAX}$ values of 61.4 (2.0) $\mathrm{ml} / \mathrm{min} / \mathrm{kg}$ for 15 male sailors compared with 64.9

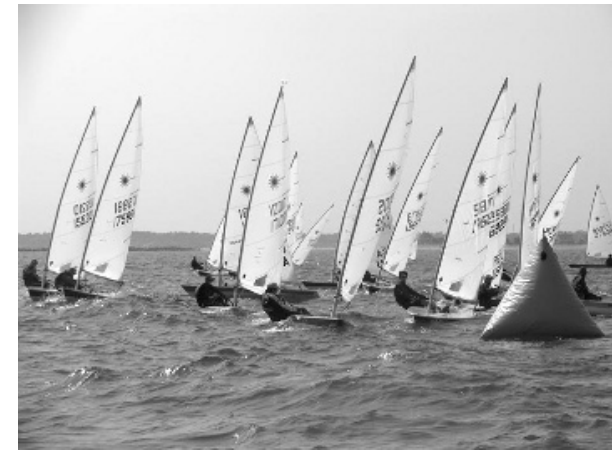

Figure 3 Lasers racing upwind at Wrightsville Beach.

(1.4) $\mathrm{ml} / \mathrm{min} / \mathrm{kg}$ for eight highly trained controls. Non-hikers displayed significantly lower rates of 58.6 (3.8) $\mathrm{ml} / \mathrm{min} / \mathrm{kg}$ than hikers at $63.8(1.7) \mathrm{ml} / \mathrm{min} / \mathrm{kg}$. Eight female sailors had significantly lower $\mathrm{VO}_{2} \mathrm{MAX}$ of 50.1 (1.4) $\mathrm{ml} / \mathrm{min} / \mathrm{kg}$. In 1995 , Vogiatzis et al ${ }^{59}$ found a mean $\mathrm{VO}_{2} \mathrm{MAX}$ among eight elite male Laser sailors of $52(6) \mathrm{ml} / \mathrm{min} / \mathrm{kg}$.

Bojsen-Moller et $a l^{56}$ studied 38 sailors on the Danish Olympic team in 2002, covering seven classes of sailboats. Classified into four male groups, Laser sailors had the highest $\mathrm{VO}_{2} \mathrm{MAX}$, at $58.3(4.2) \mathrm{ml} / \mathrm{min} / \mathrm{kg}$, and the Finn and Star sailors had the lowest, at 47.6 (3.5) $\mathrm{ml} / \mathrm{min} / \mathrm{kg}$. Values for helmsmen and crew on trapeze boats were 55.3 (4.0) and 57.3 (3.7) $\mathrm{ml} / \mathrm{min} / \mathrm{kg}$ respectively. Female Europe sailors had $\mathrm{VO}_{2} \mathrm{MAX}$ of $47.3(4.9) \mathrm{ml} / \mathrm{min} / \mathrm{kg}$, and the mean value for female 470 crew was $49.5(2.5) \mathrm{ml} / \mathrm{min} / \mathrm{kg}$. In their America's Cup study, Bernardi et al $l^{53}$ reported $\mathrm{VO}_{2} \mathrm{MAX}$ values ranging from 44.67 (4.1) ml/min/kg for trimmers to 51.93 (3.2) $\mathrm{ml} /$ $\mathrm{min} / \mathrm{kg}$ for bowmen.

\section{Strength and endurance}

Larsson et $a l^{58}$ found consistently high levels of isometric trunk strength, hiking endurance, and arm endurance in sailors versus non-sailors. Superior hiking endurance was felt to reflect high levels of endurance in knee extensors and core musculature. Bojsen-Moller et $a l^{56}$ found excellent knee extensor strength for hikers, although reduced hamstring to quadriceps strength ratios were worrisome as indicators for potential injury.

\section{Physiological variables correlated to sailing performance}

Shephard ${ }^{30}{ }^{51}$ has referenced Niinimaa's work from 1977 in which heavy wind performance was related to aerobic endurance, strength, balance, anaerobic tolerance, and resistance of mental fatigue, whereas light wind performance correlated only with high resting blood glucose concentrations. In 1994 Legg et al ${ }^{52}$ conducted a battery of physical performance measures involving 31 New Zealand Olympic sailors, comparing them with 108 international Olympic sailors. There were no "straightforward, strong and clearly identifiable" correlations of strength and aerobic measures with sailing performance, although results were limited by small sample sizes within each class of boat. Another study by Legg et $\mathrm{al}^{43}$ involving sailors in the 1996 Olympic Games showed inconsistent correlations of physical fitness and racing results in both light and heavy wind regattas. These results were also limited to a small number of races and sailors.

Vangelakoudi and Vogiatzis ${ }^{57}$ found that elite status and national rankings of Laser sailors correlated strongly with quadriceps maximal voluntary contraction (MVC), isometric endurance, and tolerance of muscular fatigue. Tan et $a l^{60}$ assessed 35 Laser sailors at a national championship. For 
male competitors, only body mass and three minute maximal effort on a hiking dynamometer correlated moderately with racing scores; female competitors did not display any significant correlations. Other measures included age, experience, height, abdominal crunches, jump power and height, cycling time to exhaustion, absolute and relative maximum isometric strength, and quadriceps strength and endurance.

\section{Physiology of small boat racing}

Most studies assessing the physiology of racing dinghies and other small sailboats have occurred in the past 10 years. This small body of literature has started to measure physiological responses to sustained muscle contraction, dynamic sailing simulators, and actual sailing.

The 1995 study of eight elite Laser sailors by Vogiatzis et al ${ }^{59}$ used a portable oxygen analyser while sailing upwind in various conditions. The mean (SD) $\mathrm{VO}_{2}$ was 20.3 (3.0) ml/ $\mathrm{min} / \mathrm{kg}$, representing $39(6) \%$ of $\mathrm{VO}_{2} \mathrm{MAX}$, and the average heart rate (HR) was 145 (21) beats/min, representing 74 (11)\% of HRMAX. The mean blood lactate concentration after the test was $2.3(0.8) \mathrm{mM}$, lower than in previous studies in which values of 4-8 $\mathrm{mM}$ were obtained after sailing tests of longer duration. Values for $\% \mathrm{VO}_{2} \mathrm{MAX}$, \%RMAX, and blood lactate concentration correlated significantly with wind speed, although the authors felt that the cardiovascular and metabolic requirements of sailing upwind are principally determined by the degree of isometric effort. Cunningham ${ }^{7}$ has reported a mean HR of 160-180 beats/min during Laser racing in winds of 10-30 knots; peaks of 190 beats $/ \mathrm{min}$ occurred at the end of the upwind legs, representing 85-95\% of HRMAX.

With small boat racing requiring some degree of sustained isometric activity, particularly while hiking, several studies have focused on related physiological variables. Using a hiking simulator, Vangelakoudi and Vogiatzis ${ }^{57}$ found a mean HR of 149 (22) beats/min with three minutes of sustained effort. Vogiatzis et $a l^{61}$ reported that, after repeated bouts on a simulator, the increase in minute ventilation was disproportionately higher than the change in oxygen uptake or blood lactate concentration; with concurrent hypocapnia confirming the occurrence of hyperventilation, this was felt to parallel the onset of fatigue. Increased quadriceps electromyographic activity also correlated with the ventilatory changes, although a direct cause-effect relation was not established.

Sustained muscle contractions above 15\% of MVC results in decreased perfusion, at which point the body compensates by increasing HR and blood pressure. ${ }^{51}$ One study found that sustained quadriceps muscle contraction at $40 \%$ of MVC resulted in a mean peak HR of 137 beats/min with a mean peak blood pressure of 198/134 mm Hg. ${ }^{30}$ If cardiovascular response to sustained muscular contraction is "proportional to the percentage of maximal force which is exerted," stronger leg and abdominal muscles should result in lower cardiovascular stress and decreased fatigue. ${ }^{51}$

Other recent studies have recognised hiking as a dynamic activity, measuring physiological responses and force demands within an active sailing environment. Through 30 minutes of simulated Laser racing by six male competitors, Cunningham and Hale ${ }^{62}$ reported that oxygen uptake peaked at $33.1 \quad(3.2) \mathrm{ml} / \mathrm{min} / \mathrm{kg} \quad\left(59.8 \quad(6.1) \%\right.$ of $\left.\quad \mathrm{VO}_{2} \mathrm{MAX}\right)$ and averaged $32.2(3.1) \mathrm{ml} / \mathrm{min} / \mathrm{kg}$ (58.6 (5.6)\% of $\left.\mathrm{VO}_{2} \mathrm{MAX}\right)$. HR peaked at 160 (10) beats/min with a mean of 156 (8) beats/ min, and blood lactate concentration increased from a baseline of $1.08(0.25) \mathrm{mM}$ to 4.47 (0.23) $\mathrm{mM}$.

Mackie et $a l^{63}$ seeking better indicators of physical demands while sailing, measured forces on hiking straps and mainsheets of the Finn, Laser, Europe, and 470 classes. A comparison of results with MVC forces on a hiking simulator showed that mean forces on the hiking strap during upwind sailing were $73-83 \%$ of predicted MVC, with peak forces exceeding predicted MVC in each class except for the 470, which had substantially lower recorded forces. Mainsheet forces upwind had a mean of $22-34 \%$ and a peak of $44-68 \%$ of predicted MVC for all classes. Forces increased with wind speed, although there was a relative plateau observed in the hiking strap force above 10-12 knots of wind speed, which may represent the point of maximal hiking effort. In a separate study of the Laser class, Mackie ${ }^{64}$ reported that hiking strap forces actually decreased when the wind increased above 10-15 knots, possibly because of changes in hiking positions during wind gusts and waves.

\section{Physiology of dinghy hiking}

Debate continues on the static versus dynamic nature of hiking as well as the most appropriate training for improving performance. $^{29} 4143515761-63$ A 1999 study by Legg et al $l^{65}$ showed that different dinghy classes spend various amounts of time in specific hiking positions, with time spent in a continuous position rarely exceeding 30 seconds. Mackie ${ }^{66}$ has reported on the development of a video analysis protocol for Europe and Laser sailors which centres on assessing hiking technique.

The physical stress of hiking has been documented since Rogge's work in 1973, and involves contraction of the quadriceps, iliopsoas, and abdominal muscles, with body weight loading the patellofemoral joint. ${ }^{30}{ }^{67}$ Incorrect technique is often a factor in hiking induced knee pain, resulting in unbalanced muscular forces around the knee joint. ${ }^{67}{ }^{68}$ With fatigue, most sailors tend to isolate the vastus lateralis, leading to patellofemoral pain; turning out both feet with the legs extended increases the workload of the vastus medialis. ${ }^{67}$ Tight toe straps and plantarflexing the foot may help to straighten the knees, centralise the force of gravity, and reduce the effort required by the quadriceps..$^{66} 67$

Fitness training specific to hiking should include muscular strength and endurance of the core and the lower extremities, maintaining balanced force and flexibility about each joint. ${ }^{51}{ }^{67}$ Training may result in increased tolerance of hiking through decreased lactate production for a given HR and $\mathrm{VO}_{2} \cdot{ }^{30}$ The use of a stationary hiking bench can benefit muscular endurance, and dynamic repetitions of trunk and sheeting movements can aid aerobic fitness. ${ }^{45}$ Training should not ignore upper body muscular development, as this is also important in counterbalancing efforts as well as sail trim. $^{51}$

In their 1998 study, Aagaard et al ${ }^{69}$ analysed several groups of sailors, assessing strength with hiking performance. For female sailors and male hikers, dynamic and static hiking performances correlated significantly with maximum eccentric and isometric knee extension strength; this did not hold true for the male non-hikers. Aagaard et al felt that the optimal hiking performance may rely on "antagonist action of the trunk and hip extensors to stabilise the lower back and spine."

In 2003, Tan et al ${ }^{60}$ reported that hiking dynamometer performances of male and female sailors correlated with maximal and repetitive knee extensor strength as well as body mass; female performance also correlated with sailing experience. Variables with no significant relation included age, height, abdominal crunches, jump power or height, cycling duration, isometric strength, quadriceps strength endurance, and the bucket test hiking time.

\section{Physiology of boardsailing}

Using a portable metabolimeter, Vogiatzis et al ${ }^{70}$ studied the physiological responses of pumping the sail. Downwind legs resulted in mean $\mathrm{VO}_{2}$ of 50.0 (8.6) $\mathrm{ml} / \mathrm{min} / \mathrm{kg}(77(8) \%$ of 
$\left.\mathrm{VO}_{2} \mathrm{MAX}\right)$ and HR of 170 (12) beats/min (87 (8)\% of HRMAX); results for upwind legs were $46.3 \mathrm{ml} / \mathrm{min} / \mathrm{kg}$ and 165 (12) beats/min. Although pumping downwind resulted in higher $\mathrm{VO}_{2}$ and $\mathrm{HR}$, upwind pumping produced higher values for the respiratory exchange ratio and the ventilatory equivalents of oxygen and carbon dioxide. The difference was felt to lie in the techniques used; downwind pumping uses motion from the entire body, whereas upwind pumping is more restrained.

\section{Nutrition and hydration}

Variable sailing environments result in a large continuum of nutritional and hydration requirements. ${ }^{71}$ Whether sailing in a one day regatta or a long distance offshore race, adequate nutrition to sustain proper blood glucose concentrations throughout the event is important for maintaining concentration and coordination. ${ }^{305172}$

\section{Day racing}

In 1996, Cunningham offered a regatta based nutrition plan, starting with a meal three hours before racing. ${ }^{7}$ Healthy snacks and fluids should be consumed throughout the day, including nutrition between races and regularly after racing to replete energy stores. Moraes et al ${ }^{12}$ reported that more than $75 \%$ of the Brazilian Olympic sailing team often had inadequate hydration and dietary intake, with an excessive protein to carbohydrate ratio. A 1997 review of 28 New Zealand Olympic sailors by Legg et al ${ }^{13}$ revealed that 39\% of sailors inadequately planned nutrition after racing, and $68 \%$ reported dehydration while racing.

\section{Offshore racing}

In long distance races, intense, vigorous activity can be supported with appropriate intake of carbohydrates, particularly foods with a low glycaemic index. ${ }^{73}$ Elite distance sailors are concerned with weight, historically to the detriment of adequate food supplies. ${ }^{71}{ }^{72}{ }^{74}$ Increasing awareness of nutritional sustenance and use of freeze dried goods has reduced this incidence, according to Pearce, who also recommends calculating anthropomorphic data and energy requirements for each sailor. ${ }^{71}{ }^{72}$ In the 1993-94 Whitbread Round the World Race, changes in body weight and composition indicated that a negative energy balance had occurred during all legs of the race. ${ }^{75}$ Energy expenditure for America's Cup sailors has been found to average $56 \mathrm{kcal} / \mathrm{kg} / \mathrm{day} .^{74}$

\section{Hydration}

Although studies are lacking in the area of hydration in sailboat racing, fluid intake is important for the sailing athlete at any level of competition. ${ }^{34}{ }^{71}$ General guidelines for hydration in sports apply to sailors. ${ }^{73}$ One recommendation is to consume $500 \mathrm{ml}$ of sports drink 30 minutes before racing, then up to $150 \mathrm{ml}$ every 15 minutes during the race, depending on environmental conditions. ${ }^{30}$ Dehydration can hamper performance, including cognitive impairment and increased injuries. ${ }^{3} 40$

\section{Sports psychology}

In recent years, there has been a growth in understanding the importance of mental skills training, especially in high level competition. ${ }^{681354}$ Relaxation techniques, pre-race routines, and mental rehearsal may be beneficial to sailors at any level. ${ }^{6}$ Olympic sailors have reported the common occurrence of nervousness, frustration, and concentration laps, with most sailors using relaxation and visualisation to cope. ${ }^{13}$

According to the 1997 report by Legg et al ${ }^{13}$ on New Zealand Olympic sailors, nearly $50 \%$ stated that they were nervous sometimes before a race. They also felt frustration with their mistakes "sometimes" (43\%) or "always" (7\%) and had negative thoughts "sometimes" (53\%) or "often" (25\%).
Eighty six per cent admitted to "sometimes" having decreased concentration at the end of races. The following self administered psychological interventions were used: relaxation $(64 \%)$, visualisation $(61 \%)$, progressive muscular relaxation (18\%), and meditation $(7 \%)$.

Sports psychology can facilitate teamwork, focus, and organisation. Using sports psychology professionals as part of a performance enhancement team is essential to the health and wellbeing of the athlete and crew.

\section{SUMMARY}

There is a growing interest in sports medicine, sports science, and human performance in the sport of sailing. The literature reviewed and the opinions provided suggest that there are injury patterns, fitness and training techniques, and physiological and psychological demands that are specific to sailing. These components of performance enhancement are specific to boat classes and crew positions and constantly change with the environment of the sport. Recognising that the value of human performance in a sport often focuses on the vessel allows the sailor athlete the opportunity to complement technology in reaching his/her goal. By addressing these components and developing further studies, knowledge of sailing will improve, injuries will be prevented, and success will be within reach.

\section{Authors' affiliations}

J B Allen, SailSportMed Inc, Wilmington, NC 28403, USA

M R De Jong, Southern Illinois Sports Medicine, Bellesville, IL, USA

Competing interests: none declared

The subjects in fig 1 have given permission for its publication.

\section{REFERENCES}

1 Barnes L. Preparation prevents sailing injuries. Physician Sportsmed 1987; 15:134-8, 141

2 Allen JB. Sports medicine and sailing. Phys Med Rehabil Clin N Am 1999;10:49-65.

3 Allen JB, Dent D, Andrews JR, et al. Sports medicine injuries in the America's Cup 2000. NZ J Sports Med, 2006; in press.

4 Crafer S. Taking the strain. Yachts and yachting Feb, 1995:4-7.

5 Young J. Prevent physical problems. Ways to avoid overuse and overexposure. Sail 1984;15:51-2, 54, 56.

6 Kent J. Performance through conditioning: sports psychology and sports medicine. Yacht racing/cruising 1981;20:83-6.

7 Cunningham P. F \& N: fitness and nutrition. Yachts and yachting Feb, 1996:10-16.

8 Shephard RJ. Biology and medicine of sailing. An update. Sports Med 1997;23:350-6.

9 Crafer S. Taking the strain. Part 2. Yachts and yachting Feb, 1995:91-4.

10 Crafer S. Body tune-up. Australian sailing Aug, 2004:55-7.

11 Scholne C. Injuries in sailing: risks and accidental injuries in sailing surveyed. NewsFlow 1994;1:6-8.

12 Moraes J, Nery C, Fontel E, et al. Multidisciplinary assessment of the Brazilian Olympic sailing team. In: Legg SJ, ed. Human performance in sailing conference proceedings: incorporating the 4th European Conference on Sailing Sports Science and Sports Medicine and the 3rd Australian Sailing Science Conference. Palmerston North, New Zealand: Massey University, 2003:92-5.

13 Legg SJ, Smith P, Slyfield D, et al. Knowledge and reported use of sport science by elite New Zealand Olympic class sailors. J Sports Med Phys Fitness 1997;37:213-17

14 Rosenbaum DA, Dietz TE. Windsurfing injuries: added awareness for diagnosis, treatment, and prevention. Phys Sportsmed 2002;30:21-2, 24.

15 Ullis KC, Anno K. Injuries of competitive board sailors. Phys Sportsmed 1984;12:86-93.

16 Allen GD, Locke S. Training activities, competitive histories and injury profiles of elite boardsailing athletes. Aust J Science Med Sport 1989;21:12-14.

17 Price C, Spalding T, McKenzie C, et al. Patterns of illness and injury encountered in amateur ocean yacht racing: an analysis of the British Telecom Round the World Yacht Race 1996-1997 [Commentary]. Br J Sports Med 2002;36:457-62.

18 Spalding T, Malinen T, Allen JB, et al. Analysis of medical problems during the 2001-2002 Volvo Ocean Race. In: Legg SJ, ed. Human performance in sailing conference proceedings: incorporating the 4th European Conference on Sailing Sports Science and Sports Medicine and the 3rd Australian Sailing Science Conference. Palmerston North, New Zealand: Massey University, 2003:47-50 
19 Allen JB. Sports Medicine Injuries in the America's Cup 2000. In: Legg SJ, ed. Human performance in sailing conference proceedings: incorporating the 4th European Conference on Sailing Sports Science and Sports Medicine and the 3rd Australian Sailing Science Conference. Palmerston North, New Zealand: Massey University, 2003:45-6.

20 Neville V, Molloy J, Speedy D. The Pain of PIN. In: Legg SJ, eds. Human performance in sailing conference proceedings: incorporating the 4th European Conference on Sailing Sports Science and Sports Medicine and the 3rd Australian Sailing Science Conference. Palmerston North, New Zealand: Massey University, 2003:65-6.

21 Neville V, Molloy J, Brooks J. Epidemiology of injuries and illnesses in America's Cup yacht racing. Br J Sports Med 2006;40:304-1 1.

22 Rodriguez R. Medical dispatches from the Whitbread Sailboat Race. Phys Sportsmed Online submission May, 1998

23 Allen JB. Sports injuries in disabled sailing. In: Legg SJ, ed. Human performance in sailing conference proceedings: incorporating the 4th European Conference on Sailing Sports Science and Sports Medicine and the 3rd Australian Sailing Science Conference. Palmerston North, New Zealand: Massey University, 2003:58

24 Allen JB, Alison B. Safety in Paralympic Sailing. Vista Conference Proceedings of the International Paralympic Committee, 2006; in press.

25 Blackburn M. The stayed back: ideas and exercises to avoid problems with the sailing spine. Australian Sailing Feb 1994:43-5, 67

26 Hall SJ, Kent JA, Dickinson VR. Comparative assessment of novel sailing trapeze harness designs. International Journal of Sport Biomechanics 1989;5:289-96.

27 Shakespeare B. No niggles: how to deal with and avoid lower back pain. Australian Sailing Jun, 2003:26-9.

28 Locke S, Allen GD. Etiology of low back pain in elite boardsailors. Med Sci Sports Exerc 1992;24:964-6.

29 McGrory BJ, Stuart MJ, Sim FH. Participation in sports after hip and knee arthroplasty: review of literature and survey of surgeon preferences. Mayo Clin Proc 1995:70:342-8

30 Shephard RJ. Injuries in sailing. In Renstrom P, eds. Clinical practice of sports injury prevention and care. Oxford: Blackwell Scientific Publications, 1994:641-54

31 Kemp R. The medical hazards of sailing. Practitioner 1975;215:188-96.

32 Hawke M, Johnson W, Baxter C. I think I'm going to be...seasick. Canadian Yachting Power and Sail 1978;3:76-7.

33 Weiss E, Jacobs M. Adventure medical kits. In A comprehensive guide to marine medicine Stamford, CT: Landfall Navigation, 2005:169-94.

34 Allen JB. Prevention of heat illness in sailors. Scuttlebutt Newsletter Published Online First, Aug 2003.

35 Payson H. Medical emergencies at sea: are you prepared? Sail 1988;19:54-6.

36 Ritchie D. Playing it safe. RYA magazine Autumn, 2002:30.

37 GAM. Unconscious. Yachting 1981;25:40-1.

38 Waggoner B, Grin OD. Concussion. American Sailor 1992;13:34-6.

39 Rubell EB. Is there a doctor onboard? Sail 1979;10:82-4.

40 Allen JB. Is weighing in a sin? J-24 Silver Anniversary Magazine Spring, 2003:8

41 Cunningham P. Olympic fit. Yachts and Yachting Oct, 1999:51-6.

42 Walls J, Bertrand L, Gale T, et al. Assessment of upwind dinghy sailing performance using a virtual reality dinghy sailing simulator. I Sci Med Sport 1998:1:61-72.

43 Legg SJ, Mackie HW, Slyfield DA. Changes in physical characteristics and performance of elite sailors following introduction of a sport science programme prior to the 1996 Olympic games. Appl Human Sc 1999;18:211-17

44 Blackburn M. Shapes \& sizes: you need to know whether you are a grunter, winger, flapper or grinder to get your body into the best shape. Australian Sailing Nov, 1998:43-4.

45 Cunningham P. Fighting fit. Yachts and Yachting Oct, 1999:40-3.

46 Scott M. Sailing fitness: you need to develop explosive power to be an ace grinder says Matt Scott. Yachts and Yachting Jul, 2003:18-19.

47 Cunningham P. Let's get physical. RYA News Winter, 1997:56-7.

48 Zelhof $\mathbf{R}$. The power to hike and trim. Six exercises to improve sailing strength in one-design sailboats. Sailing World 1990;29:SM7-9.

49 Crafer S. Stretching for success: part 2. Australian Sailing Sep, 2004:42-5

50 Zelhof R. Total strength training. Sailing World 1991;30:SM12-13.

51 Shephard RJ. The biology and medicine of sailing. Sports Med 1990;9:86-99

52 Legg SJ, Miller AB, Slyfield D, et al. Physical performance of elite New Zealand Olympic class sailors. J Sports Med Phys Fitness 1997;37:41-9.

53 Bernardi M, Fontana G, Rodio A, et al. Physiological characteristics of America's cup sailors. In: Legg SJ, ed. Human performance in sailing conference proceedings: incorporating the 4th European Conference on Sailing Sports Science and Sports Medicine and the 3rd Australian Sailing
Science Conference. Palmerston North, New Zealand: Massey University, 2003:31-5.

54 Blackburn $M$, Hubinger $L$. A winning plan: how to plan and implement a long term training program. Australian Sailing Oct, 1994:55-6.

55 Powell M. Get fit to pump. Sailing World 2000/2001;37:68-9.

56 Bojsen-Moller J, Larsson B, Magnusson SP, et al. Strength and endurance profiles of elite Olympic class sailors. In: Legg SJ, ed. Human performance in sailing conference proceedings: incorporating the 4th European Conference on Sailing Sports Science and Sports Medicine and the 3rd Australian Sailing Science Conference. Palmerston North, New Zealand: Massey University, 2003:97-111.

57 Vangelakoudi A, Vogiatzis I. Anaerobic capacity, isometric endurance and performance of Greek Laser class sailors. In: Legg SJ, ed. Human performance in sailing conference proceedings: incorporating the 4th European Conference on Sailing Sports Science and Sports Medicine and the 3rd Australian Sailing Science Conference. Palmerston North, New Zealand: Massey University, 2003:77-81.

58 Larsson B, Beyer N, Bay $\mathrm{P}$, et al. Exercise performance in elite male and female sailors. Int J Sports Med 1996;17:504-8.

59 Vogiatzis I, Spurway NC, Wilson J, et al. Assessment of aerobic and anaerobic demands of dinghy sailing at different wind velocities. J Sports Med Phys Fitness 1995:35:103-7.

60 Tan B, Aziz AR, Spurway NC, et al. Determinants of maximal hiking performance in laser sailors. In: Legg SJ, ed. Human performance in sailing conference proceedings: incorporating the 4th European Conference on Sailing Sports Science and Sports Medicine and the 3rd Australian Sailing Science Conference. Palmerston North, New Zealand: Massey University, 2003:25-30.

61 Vogiatzis I, Spurway NC, Jennett S, et al. Changes in ventilation related to changes in electromyograph activity during repetitive bouts of isometric exercise in simulated sailing. Eur J Appl Physiol Occup Physiol 1996;72:195-203.

62 Cunningham $\mathrm{P}$, Hale T. Physiological responses to 30 minutes of dynamic simulated dinghy sailing. In: Legg SJ, ed. Human performance in sailing conference proceedings: incorporating the 4th European Conference on Sailing Sports Science and Sports Medicine and the 3rd Australian Sailing Science Conference. Palmerston North, New Zealand: Massey University, 2003:19-24.

63 Mackie H, Sanders R, Legg S. The physical demands of Olympic yacht racing. J Sci Med Sport 1999;2:375-88.

64 Mackie HW. Preliminary assessment of force demands in laser racing. J Sci Med Sport 1999;2:78-85

65 Legg S, Mackie H, Smith P. Temporal patterns of physical activity in Olympic dinghy racing. J Sports Med Phys Fitness 1999:39:315-20.

66 Mackie H. Useful biomechanics for sailing: development of technique analysis protocol for Europe and Laser sailors. In: Legg SJ, ed. Human performance in sailing conference proceedings: incorporating the 4th European Conference on Sailing Sports Science and Sports Medicine and the 3rd Australian Sailing Science Conference. Palmerston North, New Zealand: Massey University, 2003:71-75.

67 Cockerill S. No pain: how to develop a hiking style that avoids the knee problems which put many out of the sport. Australian Sailing Sep, 1999:40-2.

68 Cockerill S, Taylor F. Hitch-hikers guide. Ways we can improve our hiking-out style and avoid injury. Yachts and Yachting Dec, 1998:11-15.

69 Aagaard P, Beyer N, Simonsen EB, et al. Isokinetic muscle strength and hiking performance in elite sailors. Scand J Med Sci Sports 1998;3:138-44.

70 Vogiatzis I, De Vito G, Marchetti M. The physiological responses of upwind versus downwind sail pumping on Olympic level windsurfers. In: Legg SJ, ed. Human performance in sailing conference proceedings: incorporating the 4th European Conference on Sailing Sports Science and Sports Medicine and the 3rd Australian Sailing Science Conference. Palmerston North, New Zealand: Massey University, 2003:82-6.

71 Burke LM. Nutrition for open water sailing: an interview with Jeni Pearce, sports dietitian. Int J Sport Nutr Exerc Metab 2003;13:244-9.

72 Pearce J. Just add water: specialist nutritional recommendations for off shore distance yachting events. J Sci Med Sport 2002;5:S83

73 Hay R. Fuelling offshore bodies and brains. Australian Sailing Jan, 2004:46-8.

74 Bernardi E, Fontana G, Madaffari A, et al. Nutritional requirements for an America's cup crew. In: Legg SJ, ed. Human performance in sailing conference proceedings: incorporating the 4th European Conference on Sailing Sports Science and Sports Medicine and the 3rd Australian Sailing Science Conference. Palmerston North, New Zealand: Massey University, 2003:31-5.

75 Branth S, Hambraeus L, Westerterp K, et al. Energy furnover in a sailing crew during offshore racing around the world. Med Sci Sports Exerc 1996;28:1272-6. 